Portland State University

PDXScholar

$11-22-2019$

\title{
Art Therapy and Dialectical Behavioral Therapy: a Workbook
}

Jasmine S. Griswold

Portland State University

Follow this and additional works at: https://pdxscholar.library.pdx.edu/honorstheses

Part of the Art Therapy Commons

Let us know how access to this document benefits you.

Recommended Citation

Griswold, Jasmine S., "Art Therapy and Dialectical Behavioral Therapy: a Workbook" (2019). University Honors Theses. Paper 819.

https://doi.org/10.15760/honors.838

This Thesis is brought to you for free and open access. It has been accepted for inclusion in University Honors Theses by an authorized administrator of PDXScholar. Please contact us if we can make this document more accessible: pdxscholar@pdx.edu. 


\section{Table of Contents:}

Introduction $\quad 2$

Anxiety $\quad 3$

Depression 4

Dialectical Behavioral Therapy 5

Art Therapy 7

Combining Art Therapy and DBT 9

The Purpose of this Book 10

Citations $\quad 11$

Workbook Section

Anxiety and Depression Intake Tests 13

Visual Representations of Emotions 15

Mindfulness $\quad 17$

Distress Tolerance 19

Middle Path/Grey Area 21

Emotion Regulation $\quad 23$

3 Minds Venn Diagram 25

Interpersonal Effectiveness $\quad 27$

Collage $\quad 29$

Anxiety and Depression Reflection Tests 31

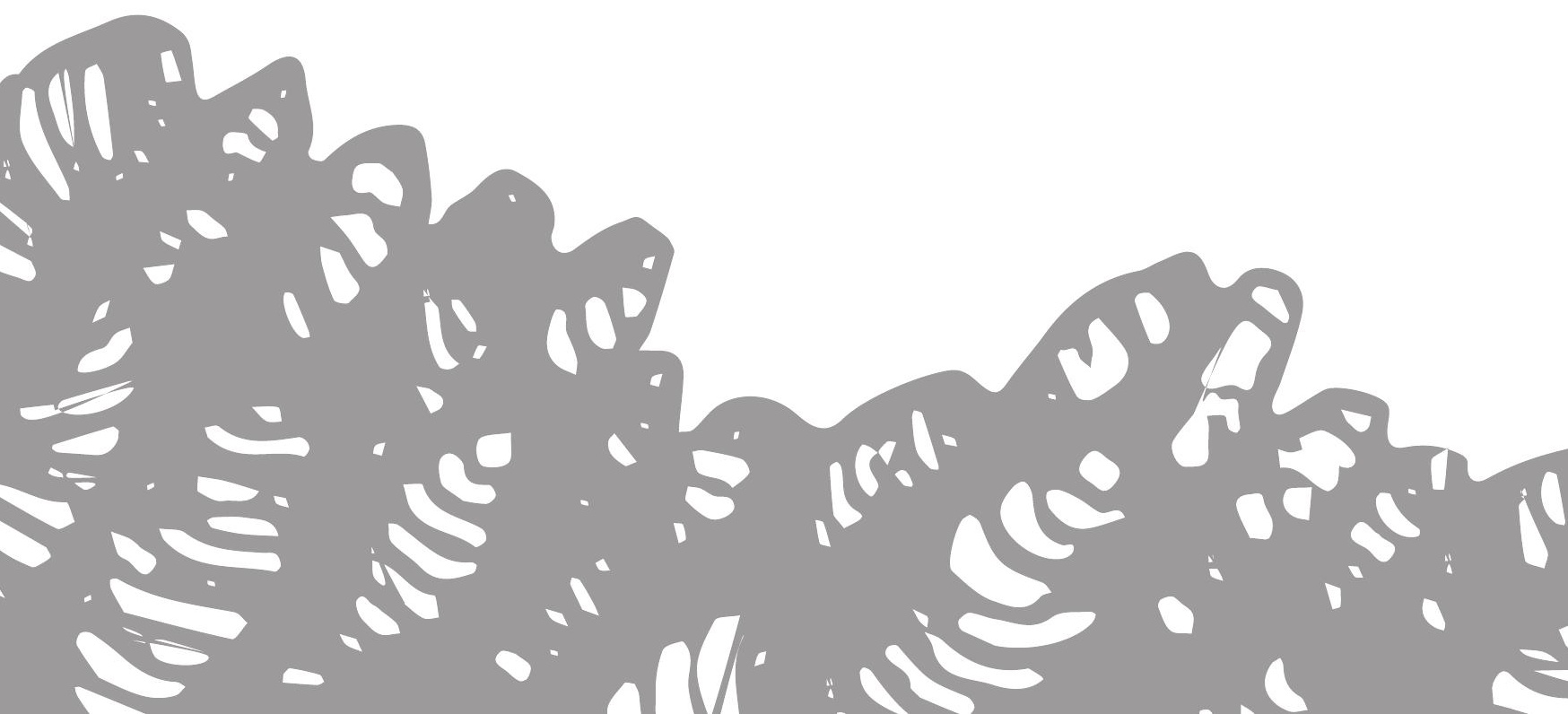




\section{Introduction:}

Looking into the ways in which we treat anxiety and depression in both clinical and casual settings it seemed apparent that there are similar tools being utilized to alleviate the effects, but there didn't seem to be a cohesion of these tools. With Dialectical Behavioral Therapy (DBT) a mindfulness based approach to therapy and the use of art as a tool to create dialogue in Art Therapy (AT) it seemed appropriate to combine the modalities to create a workbook that could be used on one's own or in conjunction with a therapist.

The research provided in the following sections will illustrate the ways in which DBT and AT have been used to reduce stress, anxiety and depression in people with post traumatic stress disorder, suicidal/self harming behavior, borderline personality disorder, and breast cancer survivors, though is not limited to those specific classifications.
As an undergraduate student at Portland State University interested art and psychology as well as the reduction of depression and anxiety, I wanted to create a prototype of what could be tested and evaluated at a later date. This project is a culmination of art and psychology; research and creation.

In my research I found things similar to my idea existed, but were not quite the same. I found a cognitive behavioral art book, or books that spoke on a more casual level about how depression and anxiety interact with our daily lives, but I found it difficult to find a book, let alone a workbook, that had art practices and therapeutic aspects. In this absence I have created my own workbook that borrows aspects from Dialectical Behavioral Therapy and Art Therapy. 


\section{Anxiety:}

Excessive fear and anxiety are what distinguish anxiety disorders from other prevalent mental illnesses. Though anxiety and fear are similar they are also different in their responses throughout the body. Anxiety is often classified as the anticipation of a threat, whereas fear is the emotional response to an immediate threat. Threat here can be in reference to physical harm or psychological danger, whether actual or perceived. As fear and anxiety are so intertwined they can impact each other in a cyclical manner. Anxiety and fear can be associated with phobias and panic disorders as well.

The body will often respond in a fight or flight response when faced with fear and anxiety.

In many cases the body will respond with but is not limited to the following:

\section{Breathing -}

Shortness of breath

(hypoventilation)

Increased breath

(hyperventilation)

Chest pain or tightness

\section{Mind Responses -}

Thoughts have slowed or accelerated

Thoughts have become jumbled or racing

Feel as if the brain is in a fog

Recurrent unwanted thoughts that cause distraction

Trouble remembering things

Trouble being in the present

\section{Gastrointestinal -}

Upset, queasy, achey, knotted

stomach

Diarrhea/constipation

Nausea or vomiting

\section{Heart Function -}

Heart fluctuation

Racing heart rate or has decreased to a slow rate

Erratic heartbeat or feels as if the heart has skipped a beat

Heartburn or burning in chest

\section{All Over Body Sensations -}

Numbness

Hands or feet feel tingly

Whole body feels strange or

different

Lightheadedness

Increase in sweating

Trembling hands or all over body 


\section{The Background of Dialectical Behavioral Therapy:}

Dialectical Behavioral Therapy (DBT) is a relatively new therapy. Starting in 1980, Dr. Marsha Linehan worked to create a therapy that prevented highly suicidal people from commiting suicide. As a young researcher Linehan had focussed on working with suicidal patients that were very difficult to treat and prevent suicides. Dr. Linehan had started developing DBT due in part to the reactions her current patients were expressing. The treatments and tools Linehan had been taught and had tried implementing did not work to her benefit with highly suicidal patients. Behavioral therapies were implemented but ultimately made the patients feel as if they were being judged and criticized, leading them to feel invalidated, they would reject this treatment. Linehan tried an acceptance based approach, and found that the patients felt as if Linehan wasn't helping them. Focusing her initial studies on Bipolar Disorder (BPD), she began developing an approach that was fluid and flexible in treatment, to meet the patient where they were.

Linehan began working to include acceptance in a way that gave room for the patient to accept themselves, their world, struggles, emotions and actions as a part of them. DBT works to train patients in skills that can help regulate their experiences and reduce feelings of extreme distress.

As a cognitive behavioral therapy DBT was first used for patients with a high risk of suicide who also had BPD. As the therapy has progressed and been researched it has been shown to effectively treat other severe disorders, including but not limited to Post Traumatic Stress Disorder (PTSD), substance abuse/dependence, depression and eating disorders.
The Linehan Institute that trains DBT therapists state the skills taught to patients on their website as:

\section{The function of DBT Skills is to help enhance a client's capabilities.}

There are four skills taught in DBT:

\section{Mindfulness:}

the practice of being fully aware and present in this one moment

\section{Distress Tolerance:}

how to tolerate pain in difficult situations, not change it

\section{Interpersonal Effectiveness:}

how to ask for what you want and say no while maintaining self-respect and relationships with others

\section{Emotion Regulation:}

how to change emotions that you want to change 


\section{Art Therapy Explained:}

As a tool of cognitive disruption to break the cycle of rumination, art therapy is used to facilitate this cognitive shift. Art therapy utilizes art making as a communication tool between client and therapist, assisting in discussion, often times also as a self evaluation. Art therapy clients often feel as if their art made through the process is a personal statement of sorts, aiding in self analysis and evaluation. Art Therapists observe and evaluate clients, with these observations they ask questions to further interpret how a client relates to their peers, family, and community.

Another key aspect of art therapy is the creation process as well as the product. The product often serves as a concrete record of process/progress. This becomes increasingly more important through the lens of mental illness wherein timelines, memories and the act of remembering are difficult. By having a concrete visual representation of therapy and self it can further help the process of therapy. Though Art Therapists don't actually analyze the art, the art making is an important aspect of the therapy. The process of art making allows art therapists to see a client's behavior, cognitive functioning and fine motor skills.

While the finalized product serves an important role, the process is just as important. The process is when the self reflection happens, where the conversation can begin, not just between client and therapist but also between themselves, serving as a mirror in some respects. Art Therapy works with the mind, body and spirit beyond the ways that traditional talk therapy does. Art Therapy incorporates kinesthetic and sensory art making opportunities.

noser
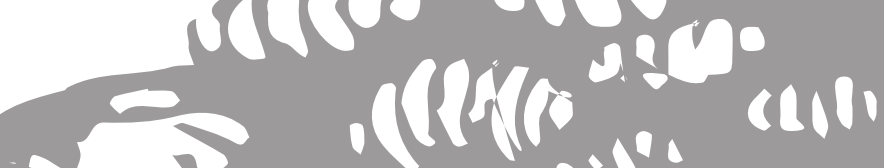

$\sin ^{-10}$

.

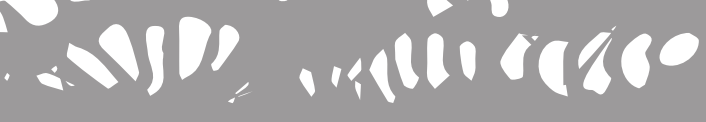

.001 


\section{Art Therapy in Research:}

This section serves as a reference to how AT has been used in conjunction with clients with cancer, work stress or PTSD. The common themes throughout each of these articles were that patients experienced anxiety, depression, or hopelessness and AT helped alleviate some of those symptoms. Though the focus of this workbook is on anxiety and depression in the broad terms of GAD and MDD, some of the key symptoms of both of those disorders are addressed in these articles. Mainly, the focus being on reduction of the general symptoms relating to depression or anxiety.

\section{Cancer Patients -}

Czamanski-Cohen, Wiley, Sela, Caspi \& Weihs, 2019

In Cancer patients, the emotional processing associated with Art Therapy has been found to relieve some feelings of depression and can help increase emotional processing. Breast cancer patients were randomized to participate in art therapy treatment or a placebo "sham" art therapy program to determine if there was any change in depression. The art therapy sessions began with an overview of art materials (colored pencils, markers, oil pastels) and ways to use them. The sessions focused on differing topics focused on increased emotional engagement and exploration/ introspective experiences. After the 60 minute art making session there was a 30 minute group discussion in which the group processed and supported one another in conjunction with an art therapist. During the "sham art therapy" sessions the groups colored mandalas for 45 minutes and had a 15 minute self care lecture, there was no introduction to art materials nor was there a focus on emotional processing. Both the Art Therapy and "Sham" Art Therapy groups reported feelings of enjoyment, while the Art Therapy group reported being able to get in touch with difficult emotions and engage in emotional processing. Emotional processing has shown improvements to mental and physical health in patients with breast cancer. Cancer in general produces stress, negative emotions and thought processes.

\section{Work Stress - \\ Chang \& Netzer, 2019}

In adults who were in good mental health, but suffered from high levels of urban work stress, art therapy practices have been found to relieve work related stress and increase enjoyment. Participants experiencing work related stress were asked to create one artwork made from traditional materials and one created using nature based materials. The participants reported that they experienced relief and were inspired to be more playful and imaginative when using the natural materials in art making. The participants expressed an overall enjoyment of the sensory experience while working with nature based materials in art making practices. The participants also mentioned that with the natural materials they were able to think about previous experiences and memories from their childhood.

\section{Post Traumatic Stress Disorder and Traumatic Brain Injury -}

Kaimal, Jones, Dieterich-Hartwell, Acharya \& Wang, 2018

Art Therapy has been found to help develop a sense of self, process trauma and reduce feelings of guilt, grief and loss in Military members experiencing PTSD and traumatic brain injuries. Patients experienced a higher sense of self after injury and increased positive emotions in relation to short term art therapy. Patients found the experience to be a positive way to process trauma. There were also decreases in grief, loss and guilt due to longer termed art therapy sessions. 


\section{The Combination of Art Therapy \\ and Dialectical Behavioral Therapy:}

Art Therapy and Dialectical Behavioral Therapy share many characteristics, while also differing in approaches. The combination of skills training paired with mindfulness in an interactive art related way seems like a way to further both disciplines.

This workbook as a combination of AT and DBT works as being a visual timeline and tool to track and contain progress, regressions, insights, feelings and thoughts. This workbook is a proactive tool that can work to create streamlined communication between oneself and a therapist when used in conjunction with a trained mental health professional.

This workbook is not a diagnostic tool and cannot act as a licensed therapist. Though this workbook is not a diagnostic tool, and should not be used as one, it can share information and insights while also being used as a communication tool and timeline.

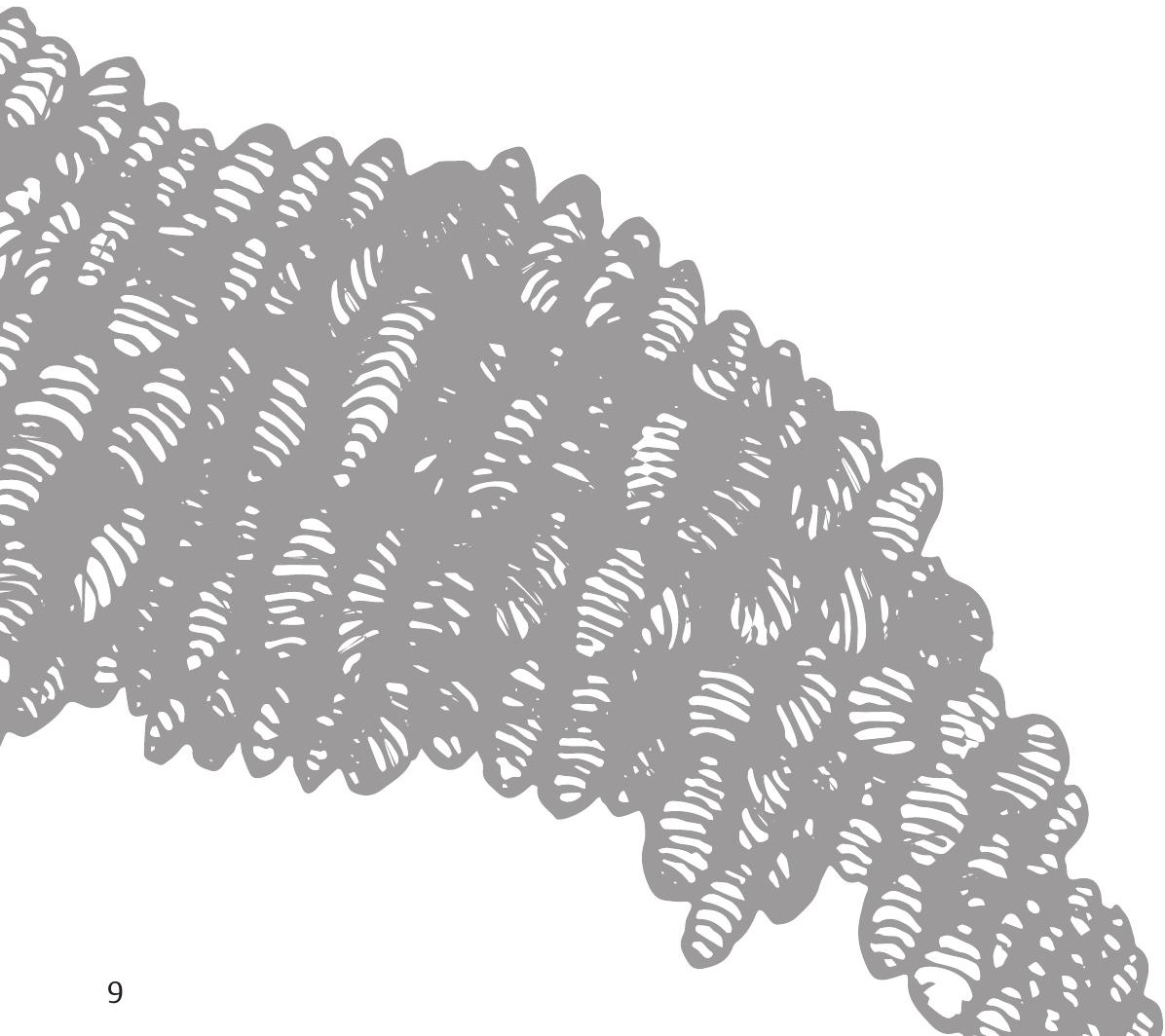




\section{The Purpose of this Book}

For the purposes of this workbook, the focus will be on symptoms of Generalized Anxiety Disorder (GAD) and Major Depressive Disorder (MDD). As well as symptoms of GAD and MDD found throughout other general anxiety and depression disorders.

Characteristics mentioned in the DSM 5 of GAD are but aren't limited to:

Excessive anxiety and worry, more days than not for at least 6 months, relating to a number of events or activities.

Difficulties managing worry.

Prominent distress expressed due to the anxiety, functioning is affected.

Key symptoms are:

Muscle tension

Fatigue

Difficulty concentrating

Irritability

Restlessness

Sleep disturbance

The worry is overwhelming and excessive to the point that it interferes with daily life and function.
Characteristics mentioned in the DSM 5 of MDD are but aren't limited to:

Depressed mood most of the day, nearly every day.

Loss of interest or pleasure in all or most daily activities for most of the day or all day.

Insomnia or hypersomnia nearly every day.

Some of the key symptoms are:

Fatigue or loss of energy

Difficulty concentrating or indecisiveness

Restlessness

Inappropriate guilt

Excessive feelings of worthlessness

Recurrent thoughts of death, suicide ideation or planning

The symptoms above can become so intense that they cause distress or impairment of daily functioning. 


\section{Citations:}

Bishop, S. R. (2004). Mindfulness: A Proposed Operational Definition. Clinical Psychology: Science and Practice, 11(3), 230-241. doi: 10.1093/ clipsy/bpho77

Chang, M., \& Netzer, D. (2019). Exploring Natural Materials: Creative Stress-Reduction for Urban Working Adults. Journal of Creativity in Mental Health,14(2), 152-168. doi:10.1080/15401383.2019. 1568940

Czamanski-Cohen, J., Wiley, J. F., Sela, N., Caspi, O., \& Weihs, K. (2019). The role of emotional processing in art therapy (REPAT) for breast cancer patients. Journal of Psychosocial Oncology,1-13. doi:10.1080/ 07347332.2019.1590491

Czamanski-Cohen, J., \& Weihs, K. (2016). The bodymind model: A platform for studying the mechanisms of change induced by art therapy. The Arts in Psychotherapy, 51, 63-71. doi: 10.1016/j. aip.2016.08.006

Definition of partial hospitalization. The National Association of Private Psychiatric Hospitals and the American Association for Partial Hospitalization. (1990). Retrieved from https://www.ncbi.nlm.nih. gov/pubmed/10106610.

Kaimal, G., Jones, J. P., Dieterich-Hartwell, R., Acharya, B., \& Wang, X. (2019). Evaluation of long- and short-term art therapy interventions in an integrative care setting for military service members with post-traumatic stress and traumatic brain injury. The Arts in Psychotherapy, 62, 28-36. doi:10.1016/j.aip.2018.10.003

Mehlum, L., Ramleth, R., Tørmoen, A. J., Haga, E., Diep, L. M., Stanley, B. H., ... Grøholt, B. (2019). Long term effectiveness of dialectical behavior therapy versus enhanced usual care for adolescents with self-harming and suicidal behavior. Journal of Child Psychology and Psychiatry. doi:10.1111/jcpp.13077
Mitchell, R., Roberts, R., Bartsch, D., \& Sullivan, T. (2019). Changes in mindfulness facets in a dialectical behaviour therapy skills training group program for borderline personality disorder. Journal of Clinical Psychology,75(6), 958-969. doi:10.1002/jclp.22744

Mochrie, K. D., Lothes, J., Quickel, E. J., John, J., \& Carter, C. (2019). From the hospital to the clinic: The impact of mindfulness on symptom reduction in a DBT partial hospital program. Journal of Clinical Psychology,75(7), 1169-1178. doi:10.1002/ jclp.22774

Remmers, C., Topolinski, S., \& Koole, S. L. (2016). Why Being Mindful May Have More Benefits Than You Realize: Mindfulness Improves Both Explicit and Implicit Mood Regulation. Mindfulness, 7(4), 829-837. doi: 10.1007/s12671-016-0520-1

Zimmerman, M., Chelminski, I., McGlinchey, J. B., \& Posternak, M. A. (2008). A clinically useful depression outcome scale. Comprehensive Psychiatry, 49(2), 131-140. http://dx.doi. org/10.1016/j.comppsych.2007.10.006

Zimmerman, M., Chelminski, I., Young, D., \& Dalrymple, K. (2010). A Clinically Useful Anxiety Outcome Scale. The Journal of Clinical Psychiatry, 71, 534- 542. 


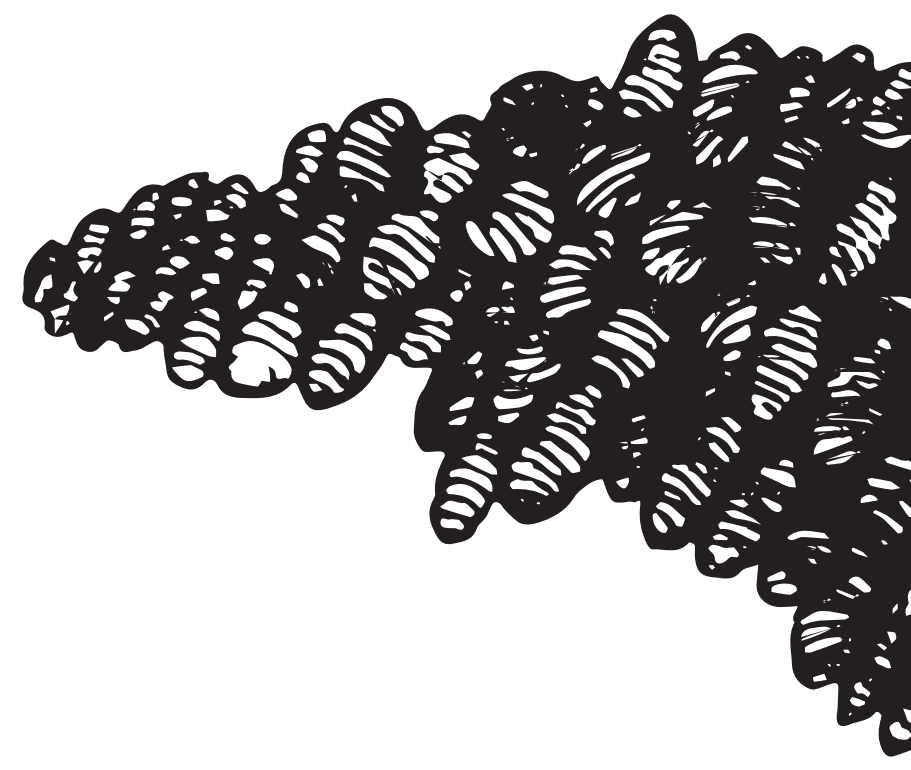

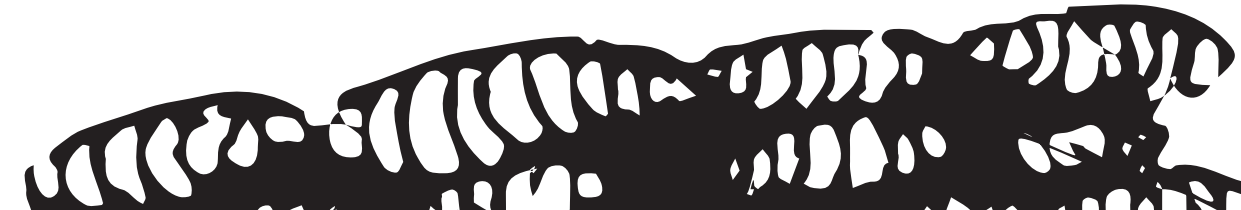

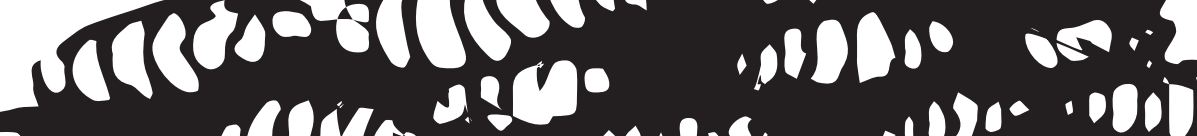

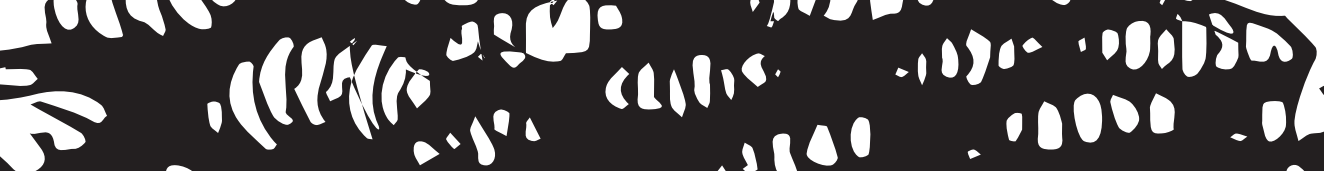

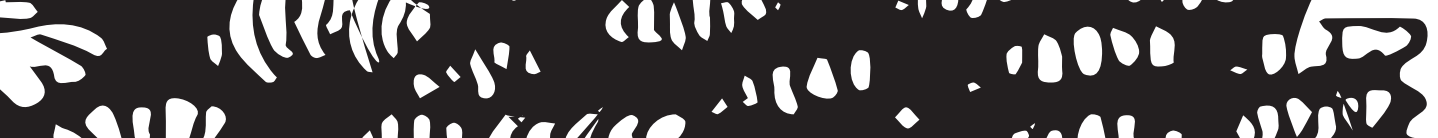

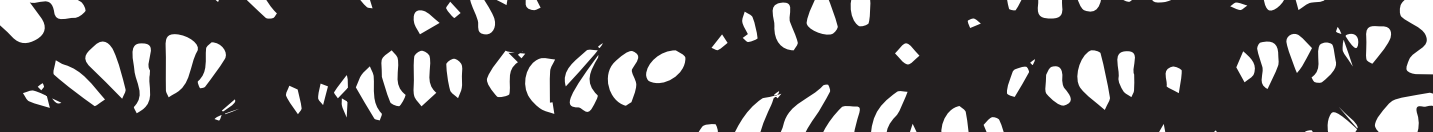

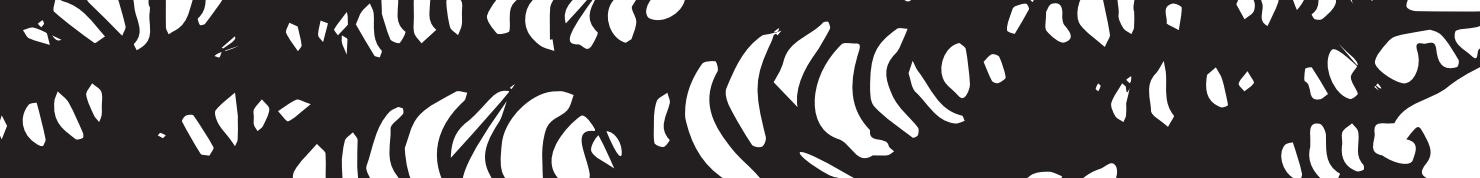

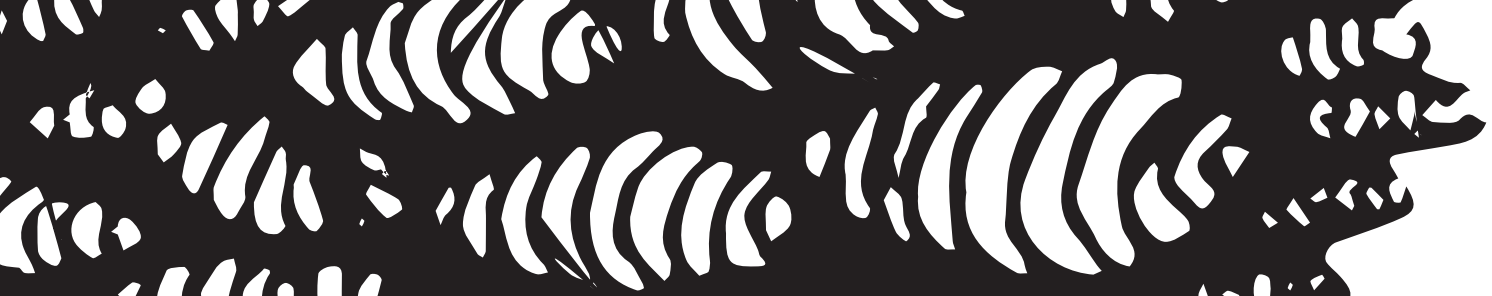
.11019 


\section{ANXIETY TEST:}

This questionnaire includes questions about symptoms of anxiety. For each item please indicate how well it describes you during the PAST WEEK, INCLUDING TODAY. Circle the number in the columns next to the item that best describes you.

RATING GUIDELINES:

0 - not at all true 1 - rarely true 2 -sometimes true 3 -often true 4 -almost always true

I felt nervous or anxious

01234

I worried a lot that something bad would happen

01234

I worried too much about bad things

01234

I was jumpy and easily startled by noises

01234

I felt "keyed up" or "on edge"

01234

I felt scared

01234

I had muscle tension or muscle aches

01234

I felt jittery

01234

I was short of breath

01234

My heart was pounding or racing

01234

I had cold, clammy hands

01234

I had a dry mouth

01234

I was dizzy or lightheaded

01234

I felt sick to my stomach (nauseated)

01234

I had diarrhea

01234

I had hot flashes or chills

01234

I urinated frequently

01234

I felt a lump in my throat

01234

I was sweating

01234

I had tingling feelings in my fingers or feet

01234

Total

\section{Scoring Instructions for the CUXOS:}

The total symptom severity score is the sum of values for items 1 through 20 , thus, the possible range of scores is o to 80 . 


\section{DEPRESSION TEST:}

This questionnaire includes questions about symptoms of depression. For each item please indicate how well it describes you during the PAST WEEK, INCLUDING TODAY. Circle the number in the columns next to the item that best describes you.

RATING GUIDELINES:

$$
\text { o-o days 1-1-2 days } \quad 2-3-4 \text { days } \quad 3-5-6 \text { days } 4-\text { every day }
$$

I felt sad or depressed

01234

I was not as interested in my usual activities

01234

My appetite was poor, and I did not feel like eating

01234

My appetite was much greater than usual

01234

I had difficulty sleeping

01234

I was sleeping too much

01234

I felt very fidgety, making it difficult to sit still

01234

I felt physically slowed down, like I was stuck in mud

01234

My energy level was low

01234

I felt guilty

01234

I thought I was a failure

01234

I had problems concentrating

01234

I had more difficulties making decisions than usual

01234

I wished I was dead

01234

I thought about killing myself

01234

I thought that the future looked hopeless

01234

\section{Total}

17. Overall, how much have symptoms of depression interfered with or caused difficulties in your life during the past week?
o) not at all
1) a little bit
2) a moderate amount
3) quite a bit
4) extremely

18. How would you rate your overall quality of life during the past week?

o) very good, my life could hardly be better

1) pretty good, most things are going well

2) the good and bad parts are about equal

3) pretty bad, most things are going poorly

4) very bad, my life could hardly be worse

\section{Scoring Instructions for the CUDOS:}

The total symptom severity score is the sum of values for items 1 through 16 . The scores on items 17 and 18 are not included in the total symptom severity score. Thus, the possible range ofvscores is o to 64 . 


\section{Visual Representation of Emotions:}

Feelings Frame that blends emotions together, to show the connectedness of emotions and the fluidity of emotional transition.

Find 5-6 difficult or important emotions that you often experience. Pick specific colors to represent those emotions and begin to fill in the first space with each of those colors as they often feel to you. Notice how some may touch or not touch then notice how they all have a place and fit into the whole picture. Notice how large or small you've made certain emotions. Journal below your feelings frame about how each color interacts with another and how much space they take up. Some questions to ponder while you journal: Which emotions take up the most space? How do each of the emotions touch? What does that mean in the context of your own life? How is it helpful that some of these emotions either touch or don't touch? 
Date: 


\section{Mindfulness:}

The practice of being fully aware and present in this one moment.

Draw an outline of your hand and focussing on the sensations of how you're feeling body wise as well as mentally. You can focus on 5 specific emotions and label each finger. Then draw the interpretations of your emotions that will all join in your palm, and think about the specific sensations drawing around your hand brings about. Think about the ways in which your hand pushes into the paper, focusing on your bodily sensations helps center you into the right now, creating a mindfulness of the present. 
Date: 


\section{Distress Tolerance:}

Visual representation of anxiety and how it shall pass.

Ride the wave.

How to tolerate pain in difficult situations, not change it. Imagine your nervous/anxious thoughts as a wave washing over you, eventually the wave settles and becomes calm. Draw an ocean wave. Write nervous/anxious thoughts in blue pencil. Color the wave in blues and greens. Notice how your nervous thoughts dissolve. Imagine these thoughts washing away as if like an ocean wave. 
Date: 


\section{Middle Path/Grey Area:}

Black and white thinking can lead to difficult situations or negative thinking to get out of.

Draw abstract spirals or shapes or phrases in black pastels on the page. Then draw different spirals or phrases in white pastel. Notice the blending of black and white into grey. Notice that the blended portion is less jarring than the polarity of the black and white. Journal about the process in which the black and white mixed into grey. Think about about the duality of both the white and black still being present in the grey. 
Date: 


\section{Emotion Regulation:}

How to change emotions that you want to change.

Acknowledge the difficult emotions or a situation. Take a deep breath, and write what the situation at hand is on the page. Begin then by thinking of the temperature of your body and picking a color to represent that. Then color around the situation in your current temperature color. Take another deep breath. Choose another color to add now that you've taken another breath. Is the emotion you're currently experiencing the same as when you started? Repeat this again. 
Has your initial emotion changed from the first emotion? Pick another color if you're experiencing a new emotion and repeat. Deep breath: Breathe in 4 seconds, hold 4 seconds then breathe out 4 seconds. Now color around the situation. Repeat as needed. Recognize the distress and discomfort, but also acknowledge the release and change in emotions indicated by the change in colors around the situation. Notice the impermanence of the distressful emotions. 


\section{Minds:}

Rational, wise, emotional.

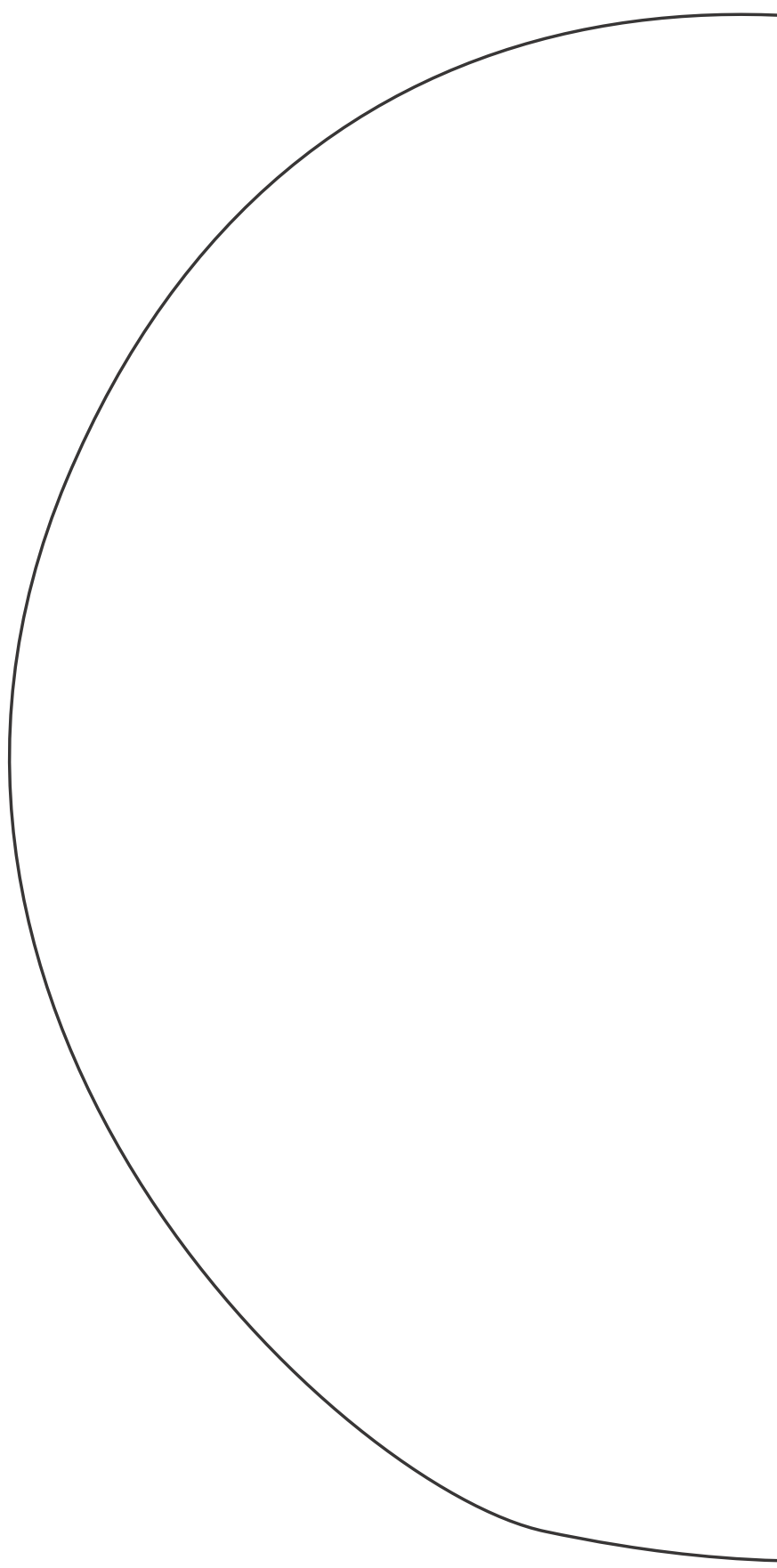

Rational. In the space to the left of the circle in the middle label that the Rational Mind. Write or draw what the rational mind means to you in that circle. What does your rational mind do? What kinds of thoughts feel rational to you? Label the circle Wise Mind. Write what the wise mind means or feels like to you. How does the wise mind incorporate rational and emotional thoughts or feelings for you? What makes this center portion wise to you? 


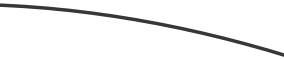




\section{Interpersonal Effectiveness:}

How to ask for what you want, and say no while maintaining self-respect and relationships with others.

Write the word "No" somewhere large on the page in white crayon. Begin journaling around the large "No" in pencil about utilizing the word "no". Using watercolors paint over the page. Notice that "no" is still a part of the conversation, and an important part of the piece, but also shows that it didn't ruin the piece or become the only part. 
Date: 


\section{Collage:}

Utilize this page to think about your current life, the life you've had, and the life you want.

Cut out shapes or images that resonate with you when you think about your life. Paste them onto the page. Journal below your collage about the choices in shapes and images you glued onto the page. 
Date: 


\section{ANXIETY TEST:}

This questionnaire includes questions about symptoms of anxiety. For each item please indicate how well it describes you during the PAST WEEK, INCLUDING TODAY. Circle the number in the columns next to the item that best describes you.

RATING GUIDELINES:

0 - not at all true 1 - rarely true 2 -sometimes true 3 -often true 4 -almost always true

I felt nervous or anxious

01234

I worried a lot that something bad would happen

01234

I worried too much about bad things

01234

I was jumpy and easily startled by noises

01234

I felt "keyed up" or "on edge"

01234

I felt scared

01234

I had muscle tension or muscle aches

01234

I felt jittery

01234

I was short of breath

01234

My heart was pounding or racing

01234

I had cold, clammy hands

01234

I had a dry mouth

01234

I was dizzy or lightheaded

01234

I felt sick to my stomach (nauseated)

01234

I had diarrhea

01234

I had hot flashes or chills

01234

I urinated frequently

01234

I felt a lump in my throat

01234

I was sweating

01234

I had tingling feelings in my fingers or feet

01234

Total

\section{Scoring Instructions for the CUXOS:}

The total symptom severity score is the sum of values for items 1 through 20 , thus, the possible range of scores is o to 80 . 


\section{DEPRESSION TEST:}

This questionnaire includes questions about symptoms of depression. For each item please indicate how well it describes you during the PAST WEEK, INCLUDING TODAY. Circle the number in the columns next to the item that best describes you.

RATING GUIDELINES:

$$
0 \text { - } 0 \text { days } \quad 1-1-2 \text { days } \quad 2-3-4 \text { days } \quad 3-5-6 \text { days } 4 \text {-every day }
$$

I felt sad or depressed

01234

I was not as interested in my usual activities

01234

My appetite was poor, and I did not feel like eating

01234

My appetite was much greater than usual

01234

I had difficulty sleeping

01234

I was sleeping too much

01234

I felt very fidgety, making it difficult to sit still

01234

I felt physically slowed down, like I was stuck in mud

01234

My energy level was low

01234

I felt guilty

01234

I thought I was a failure

01234

I had problems concentrating

01234

I had more difficulties making decisions than usual

01234

I wished I was dead

01234

I thought about killing myself

01234

I thought that the future looked hopeless

01234

\section{Total}

17. Overall, how much have symptoms of depression interfered with or caused difficulties in your life during the past week?
o) not at all
1) a little bit
2) a moderate amount
3) quite a bit
4) extremely

18. How would you rate your overall quality of life during the past week?

o) very good, my life could hardly be better

1) pretty good, most things are going well

2) the good and bad parts are about equal

3) pretty bad, most things are going poorly

4) very bad, my life could hardly be worse

\section{Scoring Instructions for the CUDOS:}

The total symptom severity score is the sum of values for items 1 through 16 . The scores on items 17 and 18 are not included in the total symptom severity score. Thus, the possible range ofvscores is o to 64 . 


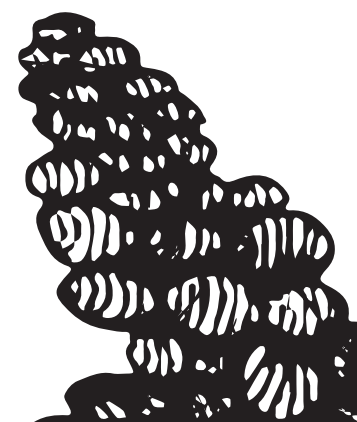

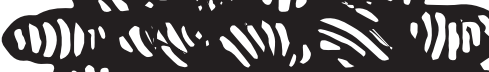

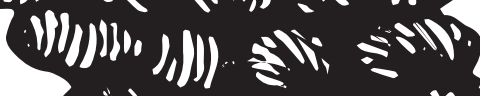
.

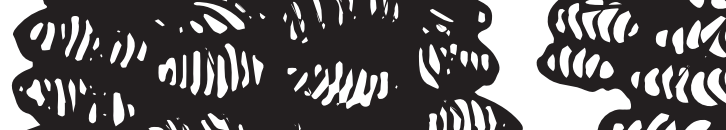

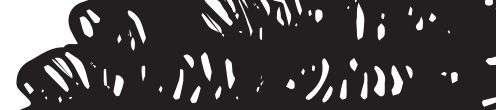
or 0 - 